\title{
AutoTest: Automation to Test Tabular Data Quality
}

\author{
Süleyman Eken, Ahmet Sayar, and Kürşat Topçuoğlu
}

\begin{abstract}
Data can take various forms and types such as numbers, symbols, words, images, and graphics. All these data are significant resources in companies' operating process. So, if data has any quality problems (e.g. poor schema design, data entry errors, misspelling, inconsistency, and etc.), it will very risky for companies. On the other hand, high quality data can increase opportunities dependent on performance issues. This study introduces an automation tool enabling data quality tests of data warehouse applications. Also with this tool, historical changes of a dataset are analyzed with linear regression algorithm and, thus, outlier variables of data trend are reported to application users. The efficiency of the proposed automation tool is also tested and results are evaluated.
\end{abstract}

Index Terms-Data quality, data integrity, test automation, data warehouse, data statistics, data filtering.

\section{INTRODUCTION}

Data is a strategic asset and assurance of data quality is becoming a business necessity in today's organizations. Companies have begun to find promising solutions enhancing the data quality. Data owned by a company might be obtained from a variety of sources such as web, databases and external resources. If data management is not done properly, money, time and other physical resources will not be used efficiently. Moreover, collected data will be bulk of rubbish rather than useful and serviceable data. Also, Global Data Management Survey stated that $75 \%$ of the companies have serious difficulties in profit/loss because of poor data quality [1]. According to TDWI (The Data Warehousing Institute) research, lost is about USD $\$ 600$ billion in a year due to poor data quality. Businesses depend on an increasing number of data intensive applications to power their strategic growth and operational efficiencies, when the quality of the data in these applications is bad it can lead to poor decision making or a serious breakdown in business operations and processes.

Incorrect or inconsistent data causes misinterpretation of the results and this situation causes misdirected users and companies. Data quality analysis is done by taking samples from the data sources by test engineers in many companies. A more comprehensive analysis of the data may be tedious and time consuming for employees due to the size of it. Investigations show that most of the problems come from overlooking incompatibility in data, not in data sources. Considering this evaluation, we developed an automation tool to cleanse inconsistent data from data sources and report outlier variables. So, test engineers or data quality

Manuscript received January 8, 2014; revised May 20, 2014.

Süleyman Eken and Ahmet Sayar are with Kocaeli University, Department of Computer Engineering, Kocaeli, Turkey (e-mail: suleyman.eken@kocaeli.edu.tr; ahmet.sayar@kocaeli.edu.tr).

Kürşat Topçuoğlu is with Turkcell Technology R\&D, Kocaeli, Turkey (e-mail: kursattopcuoglu@ gmail.com). experts can detect extraordinary data easily.

The rest of the article is structured as follows. In second section, data quality criteria's and quality problems are discussed. In the third section, relevant works on data quality tools are proposed. In fourth section, basic technologies to develop the proposed tool are given, and system architecture is discussed. Last section draws a conclusion and presents future works.

\section{DATA QUALITY DIMENSIONS AND PROBLEMS}

\section{A. Data Quality Dimensions}

A data quality dimension is an aspect or feature of information and a way to classify information and data quality needs. Dimensions are used to define, measure, and manage the quality of the data and information.

- In order to improve information quality, there must be a way to measure it.

- There is no industry standard for the types of data quality dimensions.

Reason of different quality dimensions is that different tools, techniques, and processes are used to assess, measure, and manage the various dimensions of quality. High quality data need to pass a set of quality tests. Data quality criteria offer a way for measuring and managing qualities of data [2]. Some dimensions of criteria are listed in Table I:

\begin{tabular}{|l|l|}
\multicolumn{2}{|c|}{ TABLE I: DATA QUALITY DIMENSIONS } \\
\hline Dimension & Function \\
\hline Accuracy & $\begin{array}{l}\text { The degree of conformity of a measure to a } \\
\text { standard or a true value [3]. }\end{array}$ \\
\hline Completeness & $\begin{array}{l}\text { The degree to which all required measures are } \\
\text { known [4]. }\end{array}$ \\
\hline $\begin{array}{l}\text { Consistency and } \\
\text { Synchronization }\end{array}$ & $\begin{array}{l}\text { The degree to which a set of measures are } \\
\text { equivalent across systems [5]. }\end{array}$ \\
\hline Currency & The degree to which a datum is up-to-date [6]. \\
\hline Duplication & $\begin{array}{l}\text { The degree of unwanted duplication existing } \\
\text { within or across systems for a particular field, } \\
\text { record, or data set [2]. }\end{array}$ \\
\hline Uniformity & $\begin{array}{l}\text { The degree to which a set data measures are } \\
\text { specified using the same units of measure in all } \\
\text { systems. }\end{array}$ \\
\hline Usability & $\begin{array}{l}\text { The degree to which information is clear and } \\
\text { easily used [7]. }\end{array}$ \\
\hline Integrity & $\begin{array}{l}\text { The degree of the existence, validity, structure, } \\
\text { content and other basic characteristics of the data. }\end{array}$ \\
\hline $\begin{array}{l}\text { Timeliness and } \\
\text { Availability }\end{array}$ & $\begin{array}{l}\text { The degree to which data are current and } \\
\text { available for use as specified and in the } \\
\text { timeframe in which they are expected. }\end{array}$ \\
\hline
\end{tabular}

\section{B. Classification of Data Quality Problems}

Data quality problems generally can be divided into two classes; these are single-source and multi-source problems as shown in Table II. Single and multi source problems can also be categorized into two; these are schema level and instance level problems. Classification of data quality problems is shown in Table II. 
As a result, the goal of classifying data quality problems is to illustrate non-standard data and identify exact application of data for corresponding requirements [8].

\begin{tabular}{|c|c|c|}
\hline $\begin{array}{c}\text { Data } \\
\text { quality } \\
\text { problem }\end{array}$ & Category & Definition \\
\hline \multirow{2}{*}{$\begin{array}{l}\text { Single- } \\
\text { source } \\
\text { problem }\end{array}$} & $\begin{array}{c}\text { Schema } \\
\text { level }\end{array}$ & $\begin{array}{l}\text { Lack of integrity constraints, } \\
\text { poor schema designer } \\
\text { Uniqueness constraints } \\
\text { Referential integrity }\end{array}$ \\
\hline & $\begin{array}{c}\text { Instance } \\
\text { level }\end{array}$ & $\begin{array}{l}\text { Data entry errors } \\
\text { Misspelling } \\
\text { Redundancy Duplicates } \\
\text { Contradictory values }\end{array}$ \\
\hline \multirow{2}{*}{$\begin{array}{l}\text { Multi- } \\
\text { source } \\
\text { problems }\end{array}$} & $\begin{array}{c}\text { Schema } \\
\text { level }\end{array}$ & $\begin{array}{l}\text { Heterogeneous data models } \\
\text { and schema design } \\
\text { Naming Conflicts }\end{array}$ \\
\hline & $\begin{array}{c}\text { Instance } \\
\text { level }\end{array}$ & $\begin{array}{l}\text { Overlapping contradicting and } \\
\text { inconsistence data } \\
\text { Inconsistent aggregating } \\
\text { Inconsistent timing }\end{array}$ \\
\hline
\end{tabular}

\section{RELATED WORKS}

Some tools have been developed in data quality and data cleansing era. One of them is WizSame created by WizSoft Company. It is an innovative data quality and data cleansing software for discovering duplicate records based on the user criteria and revealing similar records suspected as being duplicate. The user of WizSame tool determines the matching criteria by defining for each field whether it is identical, similar or ignored. Also the user may define several conditions connected by the AND or OR operators to be added to the matching criteria [9]. WizSoft also developed software called WizWhy. It is a data-mining software tool that automatically reveals the if-then and ifand-only-if rules in data, and on the basis of these rules, it summarizes the data, points out interesting phenomena in the data, reveals the main patterns, points out cases deviating from the rules and issues predictions for new cases [10].

Another tool is SAS Data Quality. It approaches to data quality from every angle, including data standardization, deduplication and data correction. It enables users to establish data hierarchies and create reference data definitions, thus, users can have more control over their business information [11].

In the literature, some authors address methodology of assuring data quality. O Hoon et al. [12] propose quality assurance ontology to evaluate unexpected business rules and meaning of data value. To extract evaluate rules for data quality, they use ontology that has meanings of each word in itself. They gain the relationship among word in ontology, and then make SQL to evaluate data accuracy, especially focused on data meaning. Same authors propose MDRDP (Metadata Registry based on Data Profiling) to minimize the time and human resource for analyzing and extracting metadata as criteria standard for data profiling. Metadata Registry can guarantee the quality of metadata so that results of quality evaluation would improve [13]. Rehman and Esichaikul [14] focus on one of the major issue of data cleansing i.e. "duplicate record detection" which arises when the data is collected from various sources. Developed prototype which shows that adaptive duplicate detection algorithm is the optimal solution for the problem of duplicate record detection. For approximate matching of data records, string matching algorithms (recursive algorithm with word base and recursive algorithm with character base) have been implemented.

\section{SYSTEM ARCHITECTURE}

In the proposed system, data is processed or analyzed with appropriate statistical techniques. The proposed AutoTest tool takes into account five different statistics analysis:

- Table statistics: In this category, invariant variable values of a table are stored. The number of rows and columns in the table can be examples of this category.

- Column statistics: In this category, statistics give information about meaningful values within column and identifying the column. These statistics include standard deviation and mean values of the variables in the column and the number of unique values of the column.

- Value frequency statistics: In this category, statistics give information about how many times the values of the column repeat and if values of the column are metric, sum of these metric values are in this category. For instance, if a table contains prepaid and postpaid payment type column values, sum of these metric values are considered in this category.

- Value format statistics: In this category, statistics give information about how many times the values of the column are repeated according to the format of column values.

- Value distribution statistics: In this category, statistics give information about classification of numerical values of columns, according to minimum and maximum values.

Logic functions of AutoTest have been developed by using the PL/SQL database programming language on Oracle $11 \mathrm{G}$ Release 2 Enterprise Edition database management system [15]. Application Express (APEX) [16] is used to provide interface of AutoTest. It is integrated to Oracle database and it helps with developing user interfaces quickly. The login page interface for the proposed AutoTest is given in Fig. 1 .

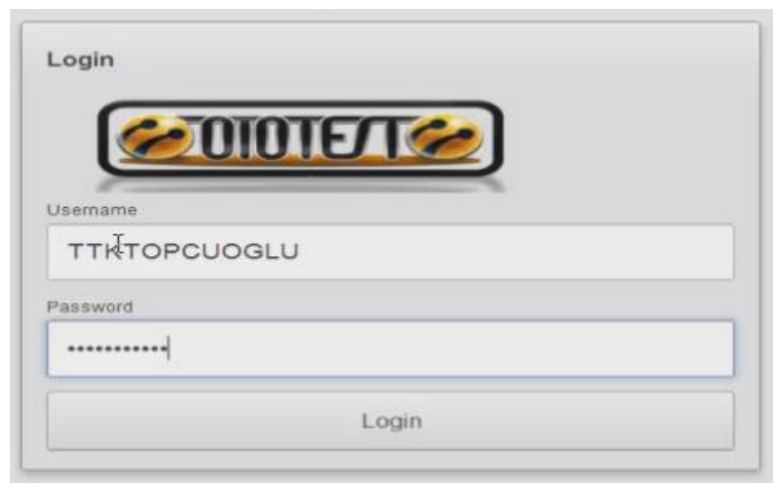

Fig. 1. Log in screen of AutoTest tool.

After logging on, the users first see the application home page (see Fig. 2). Working tasks/active jobs with name, owner, state and starting date can be seen on this page. Also, 
histories of application jobs are presented to the user in a table. The users can obtain some information such as how long successful jobs took to complete and for what reasons jobs failed. Moreover, a graphic shows the percentage of failed and successful jobs.
Value of frequency statistics information is presented to the user as shown in Fig. 3. Users can filter out a table and inspect the distribution of its values visually. In addition to this, the users can compare value frequency statistics, format statistics and distribution statistics of any two tables.

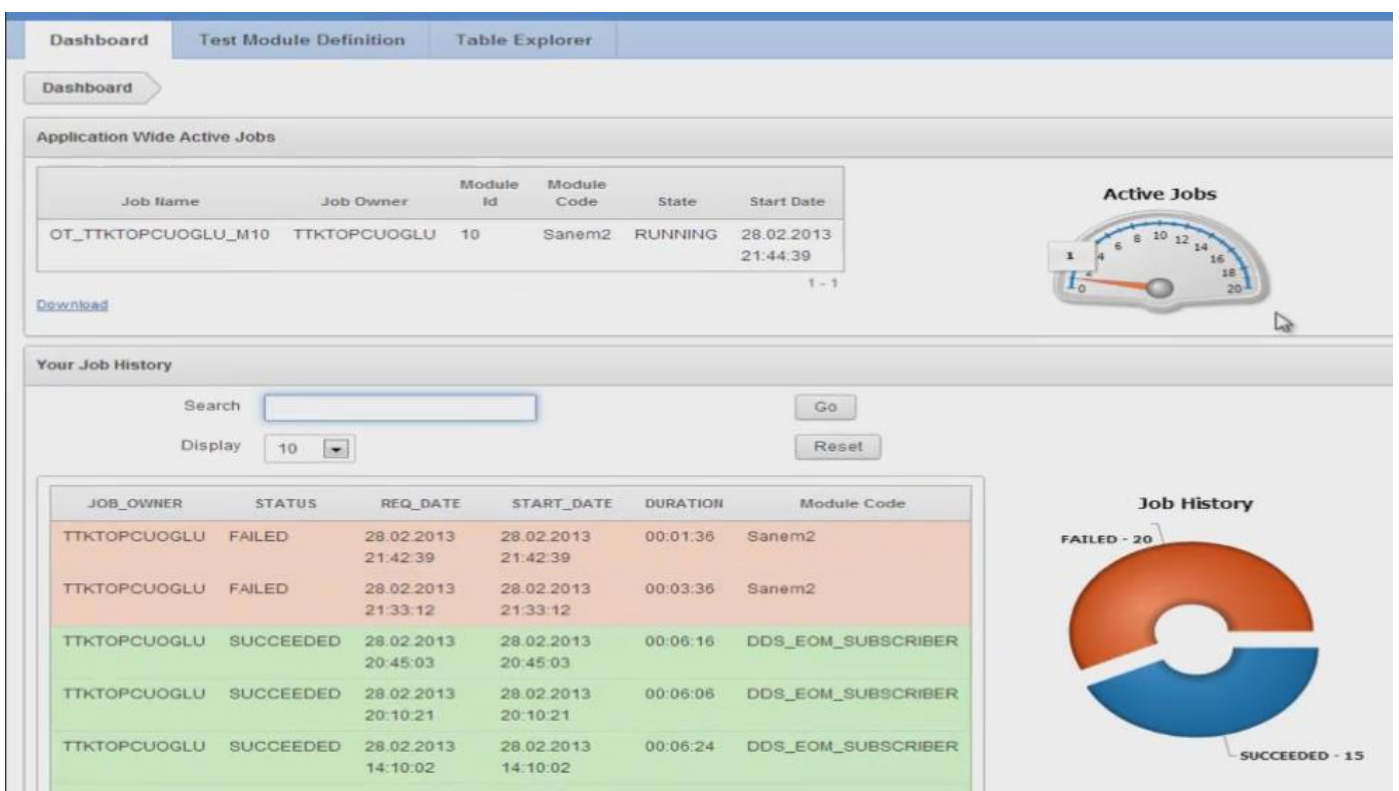

Fig. 2. AutoTest tool home page

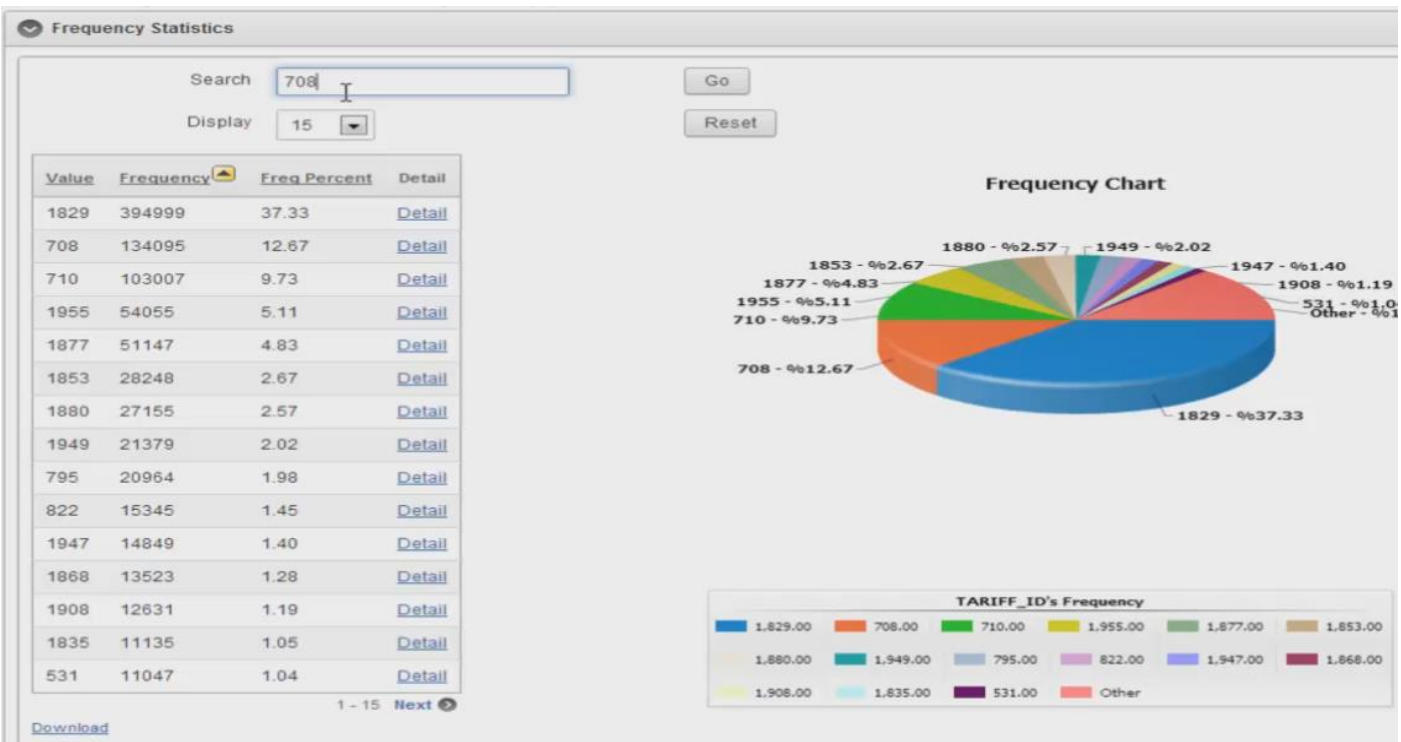

Fig. 3. Value frequency statistics.

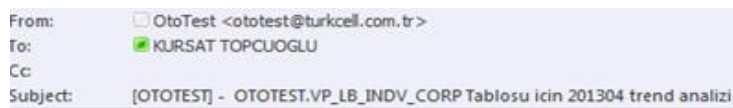

Tablo Adr: OTOTEST.VP_LB_INDV_CORP / 201304

\begin{tabular}{|c|c|c|c|c|c|}
\hline No & Column Name & Total & Average & $\begin{array}{l}\text { Null } \\
\text { Count }\end{array}$ & $\begin{array}{l}\text { Distinct } \\
\text { Count }\end{array}$ \\
\hline 1 & NUM_CHURN_CAMPAIGNS_D61 & & CRITICAL & & ERROR \\
\hline 2 & FL_SUB_GNCTRKCLL & ERROR & ERROR & & \\
\hline 3 & IN_SUB_ARPU_TRE_M6 & WARNING & WARNING & & ERROR \\
\hline 4 & IN_CAL_NUMNIGHTSMS_AVG_M6 & & & ERROR & ERROR \\
\hline 5 & DT_MNP_PORTIN & ERROR & & & \\
\hline 6 & IN_SUB_ARPU_SLO_M6 & ERROR & ERROR & & WARNING \\
\hline 7 & IN_INV_NUMLIMITALERT_M1 & & & ERROR & \\
\hline 8 & IN_INV_LIMIT_EXCESS_AVG_M3 & ERROR & & ERROR & WARNING \\
\hline 9 & VARIANCEINVOICE & ERROR & ERROR & & ERROR \\
\hline 10 & IN_INV_NUMLIMITEXCESSSDAYS_M1 & & & ERROR & \\
\hline 11 & IN_DMG_INVOICE_CONTROL_TENURE & & & ERROR & \\
\hline 12 & IN_INV_INVOICE_LIMIT_M1 & WARNING & & ERROR & \\
\hline
\end{tabular}

Fig. 4. Trend analysis results reported to the user. 
The users can examine changes in table's variables over time. This process is done with linear regression approach. After this approach, trend lines of variables will occur. When analysis is complete, outlier value are sent to users by email messages (see Fig. 4). Depending on the quantity of deviation, an alert is offered to the users at three different levels (warning, error, critical).

\section{CONCLUSION}

Data collections are very crucial for organizations' successful decision making and their businesses in general. However, there are many kinds of data quality problems stemming from many reasons and indirectly effecting or reducing the profits of the businesses, In this paper, we proposed AutoTest Tool to overcome some of these problems. AutoTest enables data quality tests of data warehouse applications, analyze historical changes of a dataset with linear regression algorithm and reports outlier variables of data trend to the user of application. In the future, we plan to integrate artificial intelligent into our system for less user interaction.

\section{REFERENCES}

[1] PWC homepage. [Online]. Available: http://www.pwc.com/

[2] D. McGilvray, "Executing data quality projects: Ten steps to quality data and trusted information," in Proc. MIT Information Quality Industry Symposium, July 15-17, 2009.

[3] C. Batini, C. Cappiello, C. Francalanci, and A. Maurino, "Methodologies for data quality assessment and improvement," ACM Computing Surveys (CSUR), vol. 41, no. 16, pp. 1-52, 2009.

[4] Y. Wand and R. Y. Wang., "Anchoring data quality dimensions in ontological foundations," Communications of the ACM, vol. 39, pp. 86-95, 1996.

[5] R. Y. Wang and D. M. Strong, "Beyond accuracy: What data quality means to data consumers," Journal of Management Information Systems, vol. 12, pp. 5-33, 1996.

[6] T. C. Redman, Data Quality for the Information Age, Artech House, 1996.

[7] S. Knight and J. Burn, "Developing a framework for assessing information quality on the World Wide Web," Informing Science: International Journal of an Emerging Trans Discipline, vol. 8, pp. 59172,2005

[8] Y. Man, L. Wei, H. Gang, and G. Juntao, "A noval data quality controlling and assessing model based on rules," in Proc. 2010 Third International Symposium on Electronic Commerce and Security (ISECS), Guangzhou, 2010, pp. 29-32.

[9] A. Meidan. Reveals duplicate records, or similar records suspected as being duplicate. [Online]. Available: http://www.wizsoft.com/index.php/products/wizsame/wizsame-whitepaper

[10] A. Meidan. A data mining tool for issuing predictions, summarizing data, and revealing interesting phenomena. [Online]. Available: http://www.wizsoft.com/index.php/products/wizwhy/ wizwhy-whitepaper

[11] D. Henschen. SAS's DataFlux Intros Management Platform, February 23, 2010.

[12] C. O. Hoon, L. J. Eun, N. H. Seok, and B. D. K. Baik, "An efficient method of data quality using quality evaluation Ontology," in Proc. Third International Conference on Convergence and Hybrid Information Technology, 2008, pp. 1058-1061.

[13] C. O. Hoon, L. J. Eun, N. H. Seok, S. K. Jae, and B. D. K. Baik, "An efficient method of data quality evaluation using metadata registry," Advanced Software Engineering \& Its Applications, pp. 9-12, 2008.

[14] M. Rehman and V. Esichaikul, "Duplicate record detection for database cleansing," Second International Conference on Machine Vision, pp. 333-338, 2009.

[15] Oracle database. [Online]. Available: http://www.oracle.com/technetwork/database/enterpriseedition/overview/index.html

[16] Oracle application express. [Online]. Available: http://apex.oracle.com/i/index.html



Süleyman Eken got his B.Sc. degree in computer engineering from Karadeniz Technical University in 2009 and M.Sc. degree in computer engineering from Kocaeli University in 2012. He is currently working towards Ph.D. degree in computer engineering from Kocaeli University, Turkey. Also, he is currently a research assistant of Computer Engineering Department at Kocaeli University in Turkey. His current research interests include satellite image processing, remote sensing, WEB-GIS and spatial databases.

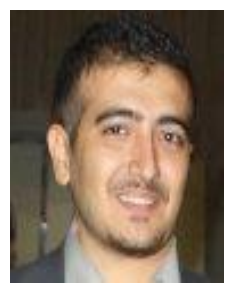

Kürşat Topçuoğlu was born in Istanbul, Turkey, in 1990. He received the B.Sc. degree in computer engineering from Kocaeli University, Kocaeli, Turkey. Also he is a student major in industrial engineering in Kocaeli University and a software developer at Turkcell Technology R\&D. His current research interests include data warehouses, data mining, and data analysis.

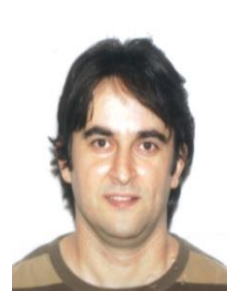

Ahmet Sayar had received his B.Sc. degree in management engineering from Istanbul Technical University, Istanbul, Turkey. He had received his M.Sc. degree in computer science from Syracuse University, NY, USA, and his $\mathrm{PhD}$ degree in computer science from Indiana University, IN, USA. He had been worked at Los Alamos National Laboratory, New Mexico, USA and Community Grids Laboratory, IN, USA as a researcher. He is currently an assistant professor at Kocaeli University Computer Engineering Department in Turkey. His current research interests include distributed systems (such as big data analytics and distributed file systems), remote sensing, WEB-GIS and exploratory spatial data analysis. 